\title{
C3 Glomerulopathy with Monoclonal Gammopathy
}

National Cancer Institute

\section{Source}

National Cancer Institute. C3 Glomerulopathy with Monoclonal Gammopathy. NCI

Thesaurus. Code C158971.

A subset of C3 glomerulopathy in which there is an associated finding of monoclonal gammopathy. 